\title{
Integrated index for drought assessment based on variable fuzzy set theory: A case study in the Yellow River basin, China
}

\author{
Shengzhi Huang ${ }^{\mathrm{a}}$, Jianxia Chang ${ }^{\mathrm{a}}$, Guoyong Leng ${ }^{\mathrm{b}, *}$, Qiang Huang ${ }^{\mathrm{a}}$ \\ a State Key Laboratory Base of Eco-Hydraulic Engineering in Arid Area, Xi'an University of Technology, Xi'an 710048, China \\ ${ }^{\mathrm{b}}$ Key Laboratory of Water Cycle and Related Land Surface Processes, Institute of Geographic Sciences and Natural Resources Research, Chinese Academy of Sciences, Beijing \\ 100101, China
}

\section{A R T I C L E I N F O}

\section{Article history:}

Received 20 March 2015

Received in revised form 6 May 2015

Accepted 14 May 2015

Available online 21 May 2015

This manuscript was handled by Andras

Bardossy, Editor-in-Chief, with the

assistance of Alon Rimmer, Associate Editor

\section{Keywords:}

Integrated drought index

Variable fuzzy set theory

Entropy weight method

Qualitative change point

The Yellow River basin

\begin{abstract}
S U M M A R Y
It is of great importance to construct an integrated drought indicator, which is of great importance to drought risk assessment and decision-making. Given the fuzzy nature of drought, the variable fuzzy set theory was applied to develop an Integrated Drought Index (IDI) combining meteorological, hydrological, and agricultural factors across the Yellow River basin in North China. The runoff and soil moisture were derived by driving the calibrated Variable Infiltration Capacity (VIC) model with observed atmospheric forcing. Furthermore, the law of mutual change of quality and quantity was adopted to identify qualitative change points of annual IDI series in the Yellow River basin. The results indicate that: (1) the Integrated Drought Index (IDI) has a better performance compared with Standardized Precipitation Index (SPI) and Standardized streamflow Index (SSFI), and it is more sensitive and effective to capture drought onset and persistence, largely owing to its combination with the information of different drought-related variables; (2) spatially, the middle reaches has a higher drought risk than the rest portions of the Yellow River basin; seasonally, drought risk in spring and winter is larger than other seasons; overall, the IDI of the basin is dominated by an insignificantly downward trend; (3) some qualitative change points of drought were identified in the Yellow River basin, and those are primarily induced by ENSO events and the construction of dams and reservoirs. This study proposed an alternative drought indicator coupled with multivariate drought-related variables by objectively determining their weights based on the entropy weight method, which has a great value in characterizing drought.
\end{abstract}

(c) 2015 Elsevier B.V. All rights reserved.

\section{Introduction}

Drought is a kind of natural recurring hazards, which is insidious and slow-onset, and it is usually well formed before it is realized as a threat (Pongracz et al., 1999). Drought can exert enormous impacts on economy, society, and environment (WGA (1996)). According to the Federal Emergency Management Agency, annual drought losses in the US were estimated to be US\$ 6-8 billion (FEMA, 1995). Droughts are perceived as one of the most cost and least understood natural hazards and impact more people than any other types of natural hazards (Wilhite, 2000). Therefore, it is of great importance to investigate drought evolution and its possible risk (Huang et al., 2014a,b).

Drought indices are critically important to assess and to monitor drought due to their abilities to simplify complex interaction among many climate and climate-related parameters. Indicators

\footnotetext{
* Corresponding author.

E-mail address: guoyong.leng@gmail.com (G. Leng).
}

allow researchers to quantitatively assess climate anomalies in terms of their frequency, severity, duration as well as spatial extent (Wilhite, 2000). Standardized Precipitation Index (SPI) is widely used as an effective drought indicator for drought assessment (Moreira et al., 2008; Mishra and Singh, 2010; Huang et al., 2014b). It was proposed by McKee et al. (1993) and was based on a specific window size, and monthly precipitation data are transformed into their corresponding cumulative probabilities which are then mapped into the standard normal distribution. The probabilistic nature of SPI makes it be comparable between different locations and variables (McKee et al., 1993). Although SPI has an extensive application in drought characterization, it can result in some confusions because of its inconsistent results caused by different window sizes (Vicente-Serrano and López-Moreno, 2005). Additionally, SPI fails to explain seasonal variability characteristic, for instance, a specific amount of precipitation should have different meaning in wet and dry seasons (Ma et al., 2015).

In addition to SPI, Palmer Drought Severity Index (PDSI) based on water budget accounting and relying on precipitation and temperature data was developed by Palmer (1965). Since PDSI 
provides an opportunity to characterize droughts based on multiple sources of data (precipitation and temperature), it soon became a popular selection in drought characterization and is widely utilized even today (Dalezios et al., 2000; Kim et al., 2003; Dai et al., 2004). However, it has several drawbacks (Alley, 1984; Guttman et al., 1992; Guttman, 1998). For example, its temporal scale is not obvious, the proposed water balance model is not solid, and its values lack a statistical (e.g. recurrence probability) and physical meaning (e.g. required rainfall depth) (Ma et al., 2015).

Droughts can be classified into three physical types: meteorological, agricultural, and hydrological droughts with respect to the shortages of precipitation, runoff, and soil moisture, respectively (Wilhite and Glantz, 1985; American Meteorological Society, 2004). A large number of drought indicators (e.g. the aforementioned drought indices (SPI and PDSI)) only reflect one aspect of the deficits in water resources. The current consensus among considerable researches is that developing drought index only based on an individual variable/index (e.g., precipitation, runoff, or soil moisture) is probably not sufficient for reliable risk assessment and reasonable decision-making (Hao and AghaKouchak, 2013). The drought conditions based on one drought-related variable may be different from those based on other different variables due to the complex physical linkages among evapotranspiration, infiltration, base flow, direct runoff, and groundwater motion. Moreover, droughts are impacted by cumulative effects of water shortages over different periods of time. Therefore, information derived from various drought-related sources is very necessary for successful and reasonable drought assessment. Some researchers adopted copula function to construct a new integrated drought index (Kao and Govindaraju, 2010; Hao and AghaKouchak, 2013). For instance, Kao and Govindaraju (2010) used copula function to capture the joint behavior of precipitation and streamflow to assess droughts; Hao and AghaKouchak (2013) developed a Multivariate Standardized Drought Index (MSDI) combining SPI and the Standardized Soil Moisture Index (SSI) to monitor drought based on copula function.

Nevertheless, copulas highly rely on an assumption that samples follow a given probability density function (PDF) (Huang et al., 2014b). In practice, many problems will come up caused by the assumption. As the complicated interactions among surface water, vegetation, atmosphere, soil and groundwater affect drought evolution processes, any of known distribution fails to capture drought quantiles (Sadri and Burn, 2012). Hence, the global assumption of copula functions tends to result in a big deviation for the low or high quantiles (Sharma, 2000). Although constructing a joint index based on copula for drought assessment provides new ideas for developing drought index, it also leads to some deviations. It is a helpful attempt to develop an integrated drought index through determining reasonable weights of hydrological, meteorological, and agricultural factors. Safavi et al. (2014) proposed an integrated indicator for drought assessment using multiple factors including meteorological, hydrological, land use and other factors. The integrated indicator contains a lot of information and can comprehensively reflect drought characteristics. However, the determination of the weights is a little subjective, thereby leading to some deviations in drought monitoring. Therefore, the entropy weight method that is an objective approach for determining weights and is widely utilized in water resources assessment (Zou et al., 2006) was applied to construct an integrated index for drought assessment combining meteorological, hydrological, and agricultural factors in this study, which is the major motivation of this study.

In nature, many phenomena, concepts, and events are fuzzy. For instance, drought and flood and flood season and non-flood season, these concepts and phenomena are fuzzy (Li et al., 2014). Droughts are extremely difficult to assess mainly because of the lack of a universally accepted drought definition. As mentioned above, droughts can be defined from a meteorological, agricultural, or hydrological viewpoint. Obviously, it is useful to categorize and integrate the different types of drought. However, the boundaries which are separating these categories are normally fuzzy (Wilhite and Glantz, 1985). Therefore, the variable fuzzy set theory that can be used to describe vague phenomena and capture their dynamic development processes was utilized in this study to develop an integrated drought indicator. Additionally, according to the law of mutual change of quality and quantity from materialist dialectics, the change in constantly altering things always start with gradual accumulation of small variation (variation of quantity), and it makes natural phenomena transform from one property to another (variation of quality) when the accumulation reaches to a certain degree (Li et al., 2014). Likewise, the development of droughts should also obey this law. Thus, the law of mutual change of quality and quantity based on variable fuzzy set theory also applied to investigate drought evolution and to detect its possible qualitative change point in the Yellow River basin.

The Yellow River is a very famous river in the world. It ranks the second largest river in China and the sixth largest river in the world in terms of its length (Shiau et al., 2007). Generally, approximately $12.6 \times 10^{6}$ ha cultivated land and 110 million residents are in the Yellow River basin (Shiau et al., 2007). However, the Yellow River is frequently suffered from droughts from ancient times to present (She and Xia, 2013). Historically, one of continuous droughts had attacked this region in 1637-1643, and the strikingly severe drought even directly triggered the demise of the Ming Dynasty (Xie and Fu, 2004). Another drought occurring between late 1920s and early 1930s had impacted approximately 20 million people, and was claimed that over 3 million lives died because of drought-related diseases and famine (Xie and Fu, 2004). Since the 1970s, the zero-flow phenomena occurring in the downstream of the Yellow River have become common and obtained wide attention. The high frequent flow interruptions during the past 30 years have caused widespread adverse impacts in agriculture, industry, and ecology. However, to date, although some scholars have researched drought evolution across the whole Yellow River basin (Xie and Fu, 2004; Shiau et al., 2007; Peng et al., 2011; She and Xia, 2013), as far as we know, all of them have assessed drought risk based on a single drought-related variable and none has adopted an integrated drought index to thoroughly investigate drought evolution characteristics in the Yellow River basin. Therefore, it is of great metric to scientifically and reasonably assess droughts based on an aggregative indicator in the Yellow River basin.

The rest of the paper is organized as follows. The second section introduces the study area and data. The methodology is provided in section three, followed by results and discussions in the fourth section. The fifth section shows the conclusions drawn from the study.

\section{Study area and data}

\subsection{The Yellow River basin}

Originating from the Qinghai-Tibet Plateau in the West China, the Yellow River flows northward, turns south and then flows eastward, and finally discharges into the Bohai Sea. It has a length of $5464 \mathrm{~km}$ and a drainage area of $752,443 \mathrm{~km}^{2}$ (Shao et al., 2006). The Yellow River basin is located between $95^{\circ} \mathrm{E}-119^{\circ} \mathrm{E}$ and $32^{\circ} \mathrm{N}-$ $41^{\circ} \mathrm{N}$ (Fig. 1). As Chinese ancestors have lived in this area since prehistoric times, the Yellow River has been called as the 'Mother River of China' for a long time (Fu et al., 2004). The annual precipitation in the Yellow River basin ranges from 123 to $1021 \mathrm{~mm}$, and 


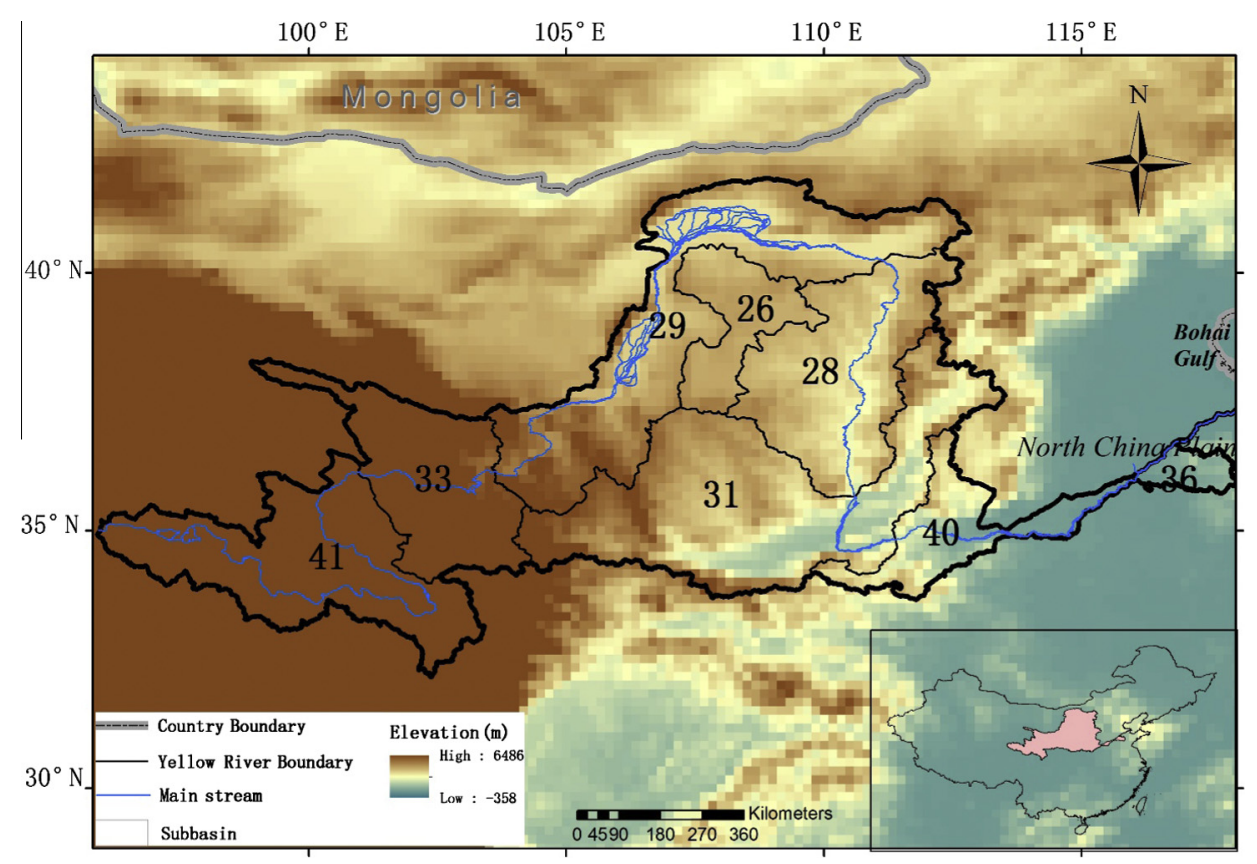

Fig. 1. Location of the Yellow River basin and its eight subzones.

its annual pan evaporation varies from 700 to $1800 \mathrm{~mm}$ (Shao et al., 2006). Due to the various topographies and large area, precipitation distribution exhibits a noticeable difference. Generally, the average annual precipitation increases from northwest to southeast at a mean level. In order to systematically analyze drought characteristics, the whole Yellow River basin was divided into eight subzones based on the secondary basin boundary in China (http://www.geodata.cn/Portal/metadata/viewMetadata. jsp?id=210008-10263), and their zone numbers are 26, 28, 29, $31,33,36,40$, and 41 , respectively (Fig. 1 ).

\subsection{Simulation of runoff and soil moisture}

The Variable Infiltration Capacity (VIC) model (Liang et al., 1994, 1996) was adopted to derive the land surface hydrological fluexs/states including runoff and soil moisture at the daily time step. It is a semi-distributed macro-scale hydrological model characterized by representing sub-grid variability in precipitation, topography, vegetation classes, soil moisture storage capacity, etc. (Liang et al., 1994, 1996; Nijssen et al., 1997). In addition, both saturation and infiltration excess runoff processes are dynamically represented in the runoff generation scheme. The model has been widely used to investigate the changes in land surface hydrology at various spatial scales (Nijssen et al., 2001; Sheffield and Wood, 2007; Shi et al., 2008; Pan and Wood, 2009; Leng et al., 2015a,b). Meteorological forcing (e.g. precipitation, temperature, wind speed) for driving the VIC model are obtained from the National Climate Center (NCC) of China Meteorological Administration (CMA), which were interpolated into 0.25 degree. Land surface characteristics such as vegetation, soil, and elevation were obtained from Nijssen et al. (2001). Six parameters, i.e. the infiltration parameter $b$, the second and third soil layer depths $\left(d_{2}, d_{3}\right)$, and the three parameters in baseflow scheme $\left(D_{m}, D_{s}, W_{s}\right)$ were calibrated to match the long-term monthly streamflow observations and validated against the observed soil moisture from the Global Soil Moisture Data Bank (Robock et al., 2000). The simulations are described in detail by Zhang et al. (2014). The dataset provides a current state-of-art estimate of land surface fluxs/states, and has great value in evaluating the long-term of the water balance components. In this study, the gridded daily precipitation and simulated runoff and soil moisture from 1952-2012 was aggregated into the monthly scale for use.

\subsection{Southern oscillation index}

The Southern Oscillation Index (SOI) is a standardized indicator based on the observed sea level pressure discrepancies between Tahiti and Darwin in Australia. It is one measure of the large-scale fluctuations of air pressure occurring between the eastern and western tropical Pacific during El Niño and La Niña episodes. Therefore, the SOI index is frequently used to investigate the linkage between El Niño/Southern Oscillation (ENSO) events and precipitation variability (Glantz et al., 1991; Wang et al., 2001, 2006). Hence, monthly SOI series covering 1952-2011 and acquired from Climatic Research Unit in University of East Anglia (http://www.cru.uea.ac.uk/cru/data/soi/) was used to investigate the influence of ENSO events on the identified qualitative change points of drought in the Yellow River basin.

\section{Methodologies}

\subsection{Entropy weight method}

Information entropy is the measure of the disorder extent of a specific system and can be used to quantify the amount of useful information among given data (Meng, 1989). When the changes in the values of the evaluating object are obvious, their entropy is small, indicating that these data provide numerous useful information, and the evaluating object should obtained a high weight; vice versa when the variations of the evaluating object are small, and the evaluating object gains a small weight (Qiu, 2002). Therefore, the entropy weight method is an objective approach for weight determination. Therefore, the entropy weight method was wisely applied in data mining (Jing et al., 2007), parameterized defuzzification (Liu, 2007), water quality assessment (Zou et al., 2006), etc. In this study, the entropy weight method was applied to determine the weights of precipitation, runoff, and soil moisture data when developing an integrated drought index. 
In an evaluation problem with $n$ evaluating objects and $m$ indicators, the entropy of $i$ th indicator is expressed as follows:

$H_{i}=-k \sum_{j=1}^{n} f_{i j} \ln f_{i j}, i=1,2, \ldots, m$

where $f_{i j}$ denotes the frequency of the ith evaluating object and the $i$ th indicator, and $f_{i j}=r_{i j} / \sum_{j=1}^{n} r_{i j}, k=1 / \ln n$. Suppose when $f_{i j}=0, \ln f_{i j}=0$. Then the weight of entropy of $i$ th indicator can be calculated as follows:

$W_{i}=\frac{1-H_{i}}{m-\sum_{i=1}^{m} H_{i}}$

where $0 \leqslant w_{i} \leqslant 1, \sum_{i=1}^{m} w_{i}=1$.

\subsection{Law of mutual change of quality and quantity based on fuzzy} theory

Suppose $A$ be a fuzzy concept of natural concept, such as runoff or precipitation. $u$ denotes the study object and stands for annual runoff or precipitation time series. $A^{C}$ and $A$ are opposite basic fuzzy attributes. For instance, $A^{C}$ is drought while $A$ is non-drought, and when $A^{C}$ denotes flood season while $A$ is non-flood season. Their corresponding relative membership degree are $\mu_{A}(u)$ and $\mu_{A^{c}}(u)$, respectively. Note that $\mu_{A}(u)+\mu_{A^{c}}(u)=1, \quad 0 \leqslant \mu_{A}(u) \leqslant 1$ and $0 \leqslant \mu_{A^{c}}(u) \leqslant 1$. The relative difference degree between the opposite basic fuzzy properties is defined as:

$D(u)=\mu_{A}(u)-\mu_{A^{c}}(u)$. When $D(u)=0$, the two fuzzy properties reach to a dynamic equilibrium, which is regarded as a gradually qualitative boundary; when $D(u)= \pm 1$, the opposite fuzzy properties reach to mutationally qualitative point. Moreover, when $D(u)>0, \mu_{A}(u)>\mu_{A^{c}}(u)$, then $A$ is the dominant property of $u$, whilst $A^{C}$ is the secondary property; vice versa when $D(u)<0, \mu_{A}(u)<\mu_{A^{c}}(u)$ (Chen and Guo, 2006).

Suppose the study object $u$ has altered, after the change point it is called $C(u)$. Similarly, $\mu_{A}(C(u))+\mu_{A^{c}}(C(u))=1,0 \leqslant \mu_{A}(C(u)) \leqslant 1$ and $0 \leqslant \mu_{A^{c}}(C(u)) \leqslant 1$.

The relative difference degree of $C(u)$ to $A$ is expressed as:

$D(C(u))=\mu_{A}(C(u))-\mu_{A^{c}}(C(u))$

(1) if $D(u) * D(C(u))<0$ and $D(C(u)) \neq \pm 1,0$, the change in natural phenomena is gradually qualitative, and this variation has exceed boundary value between quantitative and qualitative;

(2) if $D(u) * D(C(u))>0$ and $D(C(u)) \neq \pm 1,0$, the natural phenomenon is quantitative change; if $D(u) * D(C(u))=0$, the change arrives at the dynamic equilibrium point that is a the critical point of gradually qualitative change (Chen, 2012a,b);

(3) if $D(u) * D(C(u))= \pm D(u)$, the change is mutationally qualitative and significant.

(4) Based on the above theory, we can investigate the evolution of droughts and identify their possible qualitative change points of annual Integrated Drought Index (IDI) series in the Yellow River basin.

\subsection{The assessment method based on variable fuzzy set theory}

Assume an indicator matrix with $c$ grades and $m$ indicators expressed as following:

$$
Y=\left[\begin{array}{ccccc}
<a_{12} & {\left[a_{12}, b_{12}\right]} & \ldots & {\left[a_{1(c-1)}, b_{1(c-1)}\right]} & >b_{1(c-1)} \\
>a_{22} & {\left[a_{22}, b_{22}\right]} & \ldots & {\left[a_{2(c-1)}, b_{2(c-1)}\right]} & <b_{2(c-1)} \\
\ldots & \ldots & \ldots & \ldots & \ldots \\
<a_{m 2} & {\left[a_{m 2}, b_{m 2}\right]} & \ldots & {\left[a_{m(c-1)}, b_{m(c-1)}\right]} & >b_{m(c-1)}
\end{array}\right]
$$

For a convenient calculation, the above matrix is transformed as follows:

$$
Y=\left[\begin{array}{cccc}
y_{11} & y_{12} & \cdots & y_{1 c} \\
y_{21} & y_{22} & \cdots & y_{2 c} \\
\cdots & \cdots & \cdots & \cdots \\
y_{m 1} & y_{m 2} & \cdots & y_{m c}
\end{array}\right]=\left(y_{i h}\right)
$$

where $a_{i h}$ and $b_{i h}$ are the left and right boundary value of the $h$ th indicator in the $i$ th grade, respectively.

$\left\{\begin{array}{l}y_{i 1}=a_{i 2} \\ y_{i h}=\frac{a_{i h}+b_{i h}}{2}, h=2,3, \ldots,(c-1) \\ y_{i c}=b_{i(c-1)}\end{array}\right.$

Suppose $x_{i}$ of the $i$ th indicator lie in $\left[y_{i h}, y_{i(h+1)}\right]$, and the relative membership of $x_{i}$ to the $h$ th grade is calculated as follows:

$\mu_{i h}(u)=\frac{y_{i(h+1)}-x_{i}}{y_{i(h+1)}-y_{i h}}, h=1,2, \ldots, c-1$

In addition, the relative membership degree to the rest of grades is 0 . Then, the indicator matrix of the relative membership degree can be obtained.

The relative membership degree of evaluating object to $h$ grades is computed as:

$v_{h}(u)=\sum_{i=1}^{m} \omega_{i} * \mu_{i h}(u)$

where $\omega_{i}$ is the weight of the $i$ th indicator, and $\sum_{i=1}^{m} \omega_{i}=1$.

The characteristic value of the evaluating object is calculated as follows:

$H(u)=\sum_{h=1}^{c} v_{h}(u) * h$

And the corresponding integrated relative membership degree is computed as:

$\mu_{H}(u)=\frac{c-H(u)}{c-1}$

In this study, $A$ (a fuzzy concept mentioned in Section 3.2) represents no drought event, and its opposite property is drought. $\mu_{H}(u)$ is between 0 and 1 , when its value is close to 0 , it means the relative membership degree to no drought event is approximately 0 and it belongs to drought; vice versa when its value is close to 1 . The calculated $\mu_{H}(u)$ is the Integrated Drought Index (IDI) in this study. The boundary values corresponding to no drought, light drought, moderate drought, severe drought, and extreme drought based on IDI are $1,0.75-1,0.5-0.75,0.25-0.5$, and $0-0.25$, respectively.

\subsection{Standardized precipitation index (SPI) and standardized streamflow index (SSFI)}

In this study, we utilized the Standardized Precipitation Index (SPI) (McKee et al., 1993) and Standardized Streamflow Index (SSFI) (Shukla and Wood, 2008) to compare the performance of IDI. The SPI is calculated based on probability distributions of precipitation for particular monthly time scales. In this study, the 1-month SPI was gained by fitting a gamma distribution to each month separately. The gamma distribution was used since the distribution of monthly precipitation is extremely similar to a gamma distribution (McKee et al., 1993). The detailed formulation of the SPI calculation can refer to McKee et al. (1993). The calculation procedures for SSFI are similar to the SPI but by fitting a Log 
probability density function to the specific frequency distribution of runoff series.

\subsection{The modified Mann-Kendall (MMK) trend test method}

The initial Mann-Kendall (MK) trend test method recommended by the World Meteorological Organization (Mitchell et al., 1966) is a nonparametric technique to test the trend of a time series of interest. However, the MK test results are prone to be disturbed by the persistence of hydro-meteorological series. Hamed and Rao (1998) presented a modified Mann-Kendall (MMK) trend test by taking into account the lag-i autocorrelation to overcome the issue of persistence. Daufresne et al. (2009) declared that the MMK test method is more robust than MK test in capturing the trends of hydro-meteorological series. The detailed procedures in applying the MMK can be referred to Huang et al. (2014b).

\subsection{The rescaled range $(R / S)$ analysis}

The R/S analysis was first proposed by H.E. Hurst and was utilized to study the hydrological observation data of the Nile River (Oliver and Ballester, 1996). Hereafter, R/S analysis has been widely applied in morphology, cell reproduction, runoff, earthquake activity, etc. (Hosking, 1984; Wang et al., 2013). The basic thought of the $R / S$ analysis is to change the timescale of sample series and investigate its statistical law under different scales (Oliver and Ballester, 1996).

For a time series of $n$ observations $X=x_{1}, x_{2}, \ldots, x_{\mathrm{n}}$, its average series is calculated as follows:

$y(\tau)=\frac{1}{\tau} \sum_{t=1}^{\tau} x(t) \tau=1,2, \ldots$

where $\tau$ denotes interval, and it can be any of natural number.

Its deviation is calculated as follows:

$F(t, \tau)=\sum_{t=1}^{\tau} x(t) 1 \leqslant t \leqslant \tau$

Its range is estimated as follows:

$R(\tau)=\max _{1 \leqslant t \leqslant \tau} F(t, \tau)-\min _{1 \leqslant t \leqslant \tau} F(t, \tau)$

And its standard deviation is calculated as:

$S(\tau)=\left|\frac{1}{\tau} \sum_{t=1}^{\tau}(x(t)-y(\tau))^{2}\right|^{1 / 2}$

There is a certain linkage between its range and standard deviation:

$R(\tau) / S(\tau)=(C \tau)^{H}$

where $C$ is constant, and $H$ denotes the Hurst index.

Different Hurst indicators mean different types of time series. When $H=0.5$, it means that this series is totally independent; when $0<H<0.5$, it means that the future trend of the series will be opposite to the past series, and a smaller $H$ value indicates a stronger persistence (Oliver and Ballester, 1996). Whilst $H>0.5$, it indicates that the future trend of the series will be consistent with the past series, and a larger $H$ value implies a stronger persistence (Oliver and Ballester, 1996). Therefore, this method can be utilized to analyze the persistence of drought in the Yellow River basin in the near future.

\section{Results and discussions}

4.1. The weights of meteorological, hydrological and agricultural factors in the Yellow River basin

The main motivation of this study is to construct a reliable and reasonable integrated drought index which combines meteorological, hydrological and agricultural factors. Thus, the first step is to establish an indicator system of drought assessment based on meteorological, hydrological and agricultural factors. Given the actual situation of the Yellow River basin, monthly precipitation, runoff, and soil moisture anomaly percentage were utilized to build the indicator system of drought assessment in the Yellow River basin, and the detailed indicator system was mainly referred to Lei et al. (2014) and shown in Table 1.

The entropy weight method was used to calculate the weights of monthly precipitation, runoff, and soil moisture anomaly percentage series in the Yellow River basin. The computed weights in the eight subzones in the Yellow River basin are exhibited in Table 2. It can be obviously seen from Table 2 that monthly runoff anomaly percentage series has the largest weight, whilst monthly soil moisture anomaly percentage series has the smallest weight in the Yellow River basin. The entropy weight method was used in this study to determine the weights of precipitation, runoff, and soil moisture via assessing their variations degree. When their changes are obvious, their entropies are small and their weights are large, vice versa. Commonly, the changes in precipitation and runoff are far more striking than soil moisture in the Yellow River basin. For example, the coefficients of monthly precipitation, runoff, and soil moisture series covering 1952-2012 in subzone 26 are $33.3,7.2$, and 0.7 , respectively. Thus, the weight of soil moisture is largely smaller than precipitation and runoff. Thus, the integrated drought indicator primarily contains the information of meteorological and hydrological factors due to the low weight of soil moisture and its small variation. Generally, for runoff, the variation of the upstream is smaller than those of the downstream. Conversely, their changes of precipitation and soil moisture in the upstream are larger than those of the downstream. As mentioned above, approximately $12.6 \times 10^{6}$ ha cultivated land and 110 million residents are within the Yellow River basin (Shiau et al., 2007), especially for the downstream that is deeply impacted by intensifying human activities. Since runoff is sensitive to the impact of human activities (Fu et al., 2004; Wang et al., 2006), its variation of the upstream is smaller than that in the downstream.

\subsection{The integrated drought index (IDI)}

According to Section 3.3 and the calculated weights of meteorological, hydrological, and agricultural factors, the IDI of the eight subzones were obtained. Since IDI combines the joint characteristic of meteorological and hydrological factors, it should show a new perspective. In order to present the performance of IDI, the 1-month SPI and SSFI also computed to compare with the constructed IDI in the whole Yellow River basin. For better comparable visualization, SPI, SSFI, and IDI covering 2003-2012 were plotted and displayed in Fig. 2.

It can be easily observed from Fig. 2 that IDI has a high consistence with SPI and SSFI, and their correlation coefficients are as high as 0.832 and 0.848 , respectively. Additionally, their correlation coefficients in the eight subzones are shown in Table 3. Table 3 indicates that IDI has high correlation coefficients with SPI and SSFI in the eight subzones, which further verifies the consistence among the three drought indexes and the reliability of the integrated drought index. In addition, the correlation coefficients between IDI and SSFI are larger than those between IDI and SPI. 
Table 1

The indicator system of drought assessment in the Yellow River basin.

\begin{tabular}{|c|c|c|c|c|c|c|}
\hline \multirow[t]{2}{*}{ Drought types } & \multirow[t]{2}{*}{ Drought indexes } & \multicolumn{5}{|c|}{ Drought grade } \\
\hline & & No drought & Light drought & Moderate drought & Severe drought & Extreme drought \\
\hline Meteorological drought & Monthly precipitation anomaly percentage (\%) & $>-25$ & -25 to -50 & -50 to -70 & -70 to -80 & $<-80$ \\
\hline Hydrological drought & Monthly runoff anomaly percentage (\%) & $>-10$ & -10 to -30 & -30 to -50 & -50 to -80 & $<-80$ \\
\hline Agricultural drought & Monthly soil moisture anomaly percentage (\%) & $>-10$ & -10 to -30 & -30 to -50 & -50 to -80 & $<-80$ \\
\hline
\end{tabular}

Table 2

Computed weights in the eight subzones in the Yellow River basin.

\begin{tabular}{llll}
\hline Subzone number & Precipitation & Runoff & Soil moisture \\
\hline 26 & 0.20 & 0.79 & 0.01 \\
28 & 0.25 & 0.74 & 0.01 \\
29 & 0.22 & 0.77 & 0.01 \\
31 & 0.27 & 0.71 & 0.02 \\
33 & 0.23 & 0.75 & 0.02 \\
36 & 0.24 & 0.70 & 0.06 \\
40 & 0.28 & 0.69 & 0.03 \\
41 & 0.21 & 0.74 & 0.05 \\
\hline
\end{tabular}

The primary reason is that streamflow has a larger weight than precipitation, thus, the integrated drought index contains more information of hydrological factor. To further demonstrate the value of the developed IDI, the years when historical droughts occurred during 2003-2012 in the Yellow River basin were collected from census data. As YRCC $(2008,2010)$ indicated that the Yellow River basin experienced a severe drought in 2007 and 2009. The two droughts in the basin were perfectly captured by IDI shown in Fig. 2, which further verify the reliability of the constructed IDI.

It should be noted that the threshold of moderate drought in IDI is 0.5 (the solid black line in Fig. 2), whilst that of SPI and SSFI is -0.8 (the dotted black line in Fig. 2) (Hao and Aghakouchak, 2013). It can be observed from the areas covered by red oval shown in Fig. 2 that SPI is more sensitive to capture drought onset. The primary reason is that meteorological drought (deficit in precipitation) is usually the beginning of other kinds of drought, hence, SPI is more sensitive to capture drought onset. Moreover, the areas covered by black rectangle shown in Fig. 2 displays that SSFI is more capable to obtain drought persistence. Mainly due to drought propagation and runoff generation process, hydrological drought (deficit in runoff) usually responds to meteorological drought with some delay time and its duration tend to be longer than meteorological drought. Thus, SSFI is more capable to determine realistic drought persistence. Generally, IDI exhibits the identification ability of drought onset similar to SPI and drought persistence similar to SSFI, largely owing to being successfully coupled with the information of different drought-related variables. It can be clearly seen from Fig. 2 that in most case when SPI or SSFI identifies drought, IDI always can capture the related drought. Besides, in the case when both of SPI and SSFI do not detect drought, whereas IDI can identify drought condition. The results indicates that IDI is more sensitive and effective to capture drought owing to combining the information of meteorological, hydrological, and agricultural droughts. Similarly, the comparative results among the three kinds of drought indicators in each sub-zone in the Yellow River basin are same as the whole basin, and their relevant figures are omitted for brevity. Hence, IDI has the coupled advantages of SPI and SSFI, meanwhile, reflecting a certain variation of soil moisture. Therefore, the calculated IDI is a reliable and comprehensive indicator for drought assessment, which can be adopted to scientifically investigate drought evolution in the Yellow River basin.

\subsection{The spatial characteristic of drought in the Yellow River basin}

In order to comprehensively investigate the spatial characteristic of drought in the Yellow River basin, the IDI coupled with meteorological, hydrological and agricultural factors was adopted in this study. The spatial distribution of average annual IDI in the Yellow River basin is exhibited in Fig. 3. It can be obviously observed from Fig. 3 that the annual IDI in the Yellow River basin has a noticeable spatial discrepancy. In general, the upstream of the Yellow River has a lower IDI value than the middle and downstream, indicating that the drought risk in the upstream is smaller

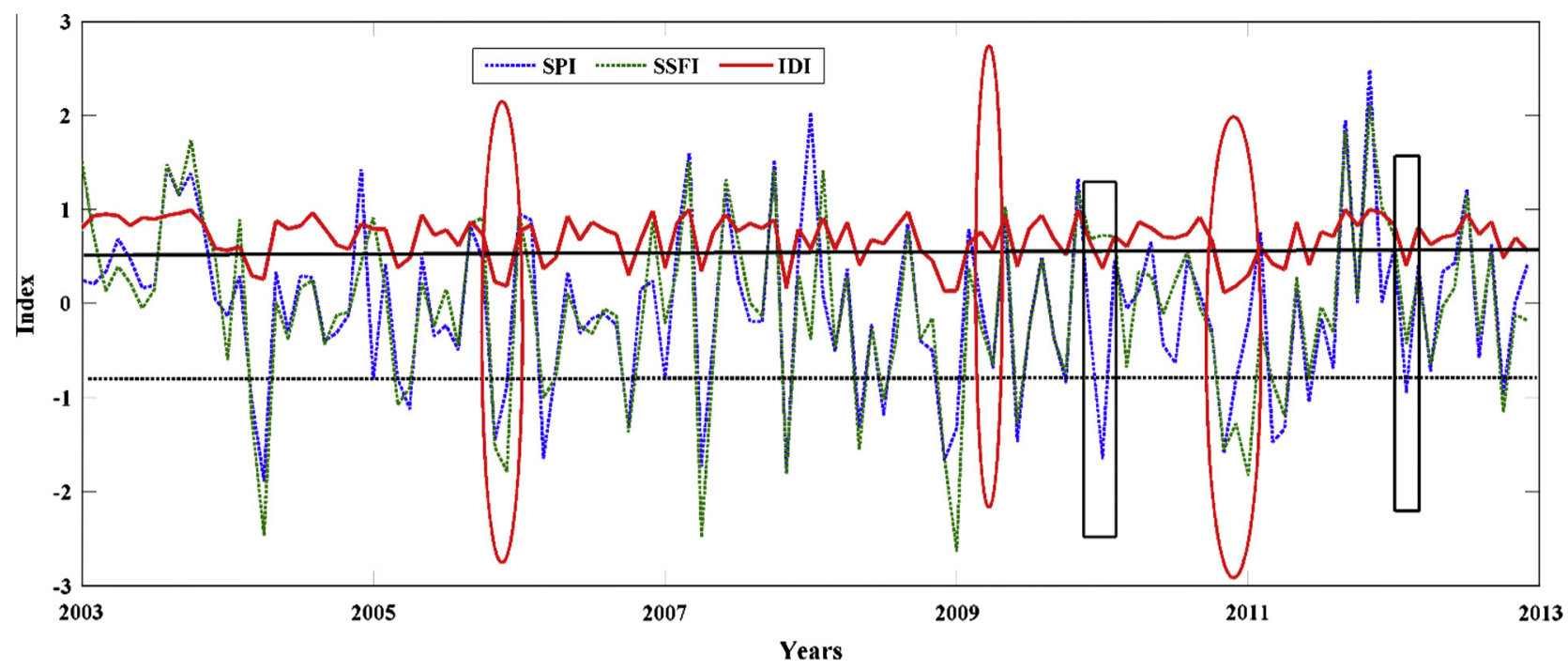

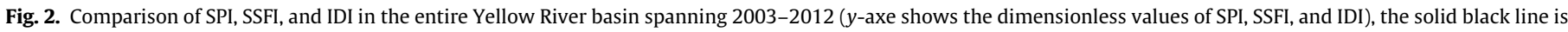
the threshold of moderate drought in IDI, while the dotted black line denotes the threshold of moderate drought in SPI and SSFI. 
Table 3

The correlation coefficients between IDI and SPI/SSFI in the eight subzones.

\begin{tabular}{lll}
\hline Subzones & SPI & SSFI \\
\hline 26 & 0.78 & 0.86 \\
28 & 0.80 & 0.85 \\
29 & 0.76 & 0.84 \\
31 & 0.79 & 0.84 \\
33 & 0.74 & 0.81 \\
36 & 0.85 & 0.86 \\
40 & 0.84 & 0.88 \\
41 & 0.63 & 0.77 \\
\hline
\end{tabular}

than the rest parts of the basin. The middle reaches have the smallest IDI, implying that its drought risk is highest in the Yellow River basin. Overall, the annual IDI decreases from south to north in the basin, which means that drought risk increases from south to north. It should be noted here that subzone 26 primarily situated in the Loess Plateau areas where the ecology and environment is extremely fragile has the largest IDI value, implying that the drought risk in this region is high. It is very difficult for this drought-prone region to recover and improve local ecology and environment. This result is similar to Huang et al. (2014b).

In addition to investigating the spatial distribution characteristics of drought in the Yellow River basin on annual scale, we also analyzed its spatial distribution features on seasonal scale (Fig. 4). Obviously, the drought in spring and winter is more severe than other seasons, and that in winter is the most severe in the Yellow River basin, while that in summer is the least severe. For the upstream, the drought pattern has little variation during various seasons, whilst that of the middle and downstream of the Yellow River has a noticeable change during different seasons. It is worth to mention that drought of subzone 26 is more severe than the rest parts of the basin, which is similar to its annual IDI characteristic. In general, the drought patterns in spring and winter are similar to the annual drought pattern.

\subsection{The temporal trend and persistence of drought}

The modified MK (MMK) method was adopted to calculate the temporal trend of drought in the Yellow River basin, and the computed trends of monthly IDI are shown in Table 4. Generally, the monthly IDI of the Yellow River basin is dominated by an insignificantly downward trend, which is consistent with She and Xia (2013), implying that the Yellow River basin has a certain tendency toward wet and the drought risk tends to reduce. For the subzone 31 which is located in the middle and south of the basin, its IDI values in March, April, and November have a significantly decreasing trend at $95 \%$ confidence level. The decreasing months are primarily concentrated in March, April, October, November, and December in the Yellow River basin. However, for February, the basin is mainly characterized by an insignificantly increasing trend. On the whole, the decreasing trend of IDI in the middle stream is more obvious than the rest parts of the basin. Furthermore, the trends of annual IDI in the eight subzones are exhibited in Table 5.

Table 5 indicates that the whole Yellow River basin is characterized by an insignificantly decreasing annual IDI except for subzone 31 that is situated in the middle and southern basin and characterized by a significantly decreasing annual IDI at $95 \%$ confidence level. In order to further know the persistence of drought in the near future, which is of great significance to drought mitigation and water resources management, the R/S analysis was used to compute the Hurst indexes of the IDI series in the eight subzones, which are shown in Table 5. The Hurst indexes of subzone 26, 29, and 41 are larger than 0.5 , implying that the decreasing trends of IDI in the headwaters area and middle stream will be persistent in the near future, whilst Hurst indexes of subzone 28, 33, 36 and 40 are smaller than 0.5 , indicating that the downward trend of IDI in the section between Tangnaihai and Lanzhou stations and the downstream will be opposite in the near future. Regarding subzone 31, the Hurst index of its IDI series is 0.5 , implying that this IDI series is totally independent and no obvious persistence of drought can be obtained.

\subsection{Identification of qualitative change points of drought and possible reasons}

As materialist dialectics indicates, natural events often begin with quantitative change, and it will lead to qualitative change when the accumulation of quantitative change reaches to a certain degree. Therefore, it is very necessary to identify quantitative change points of drought in the Yellow River basin, which helps to reveal drought evolution, thereby promoting local drought

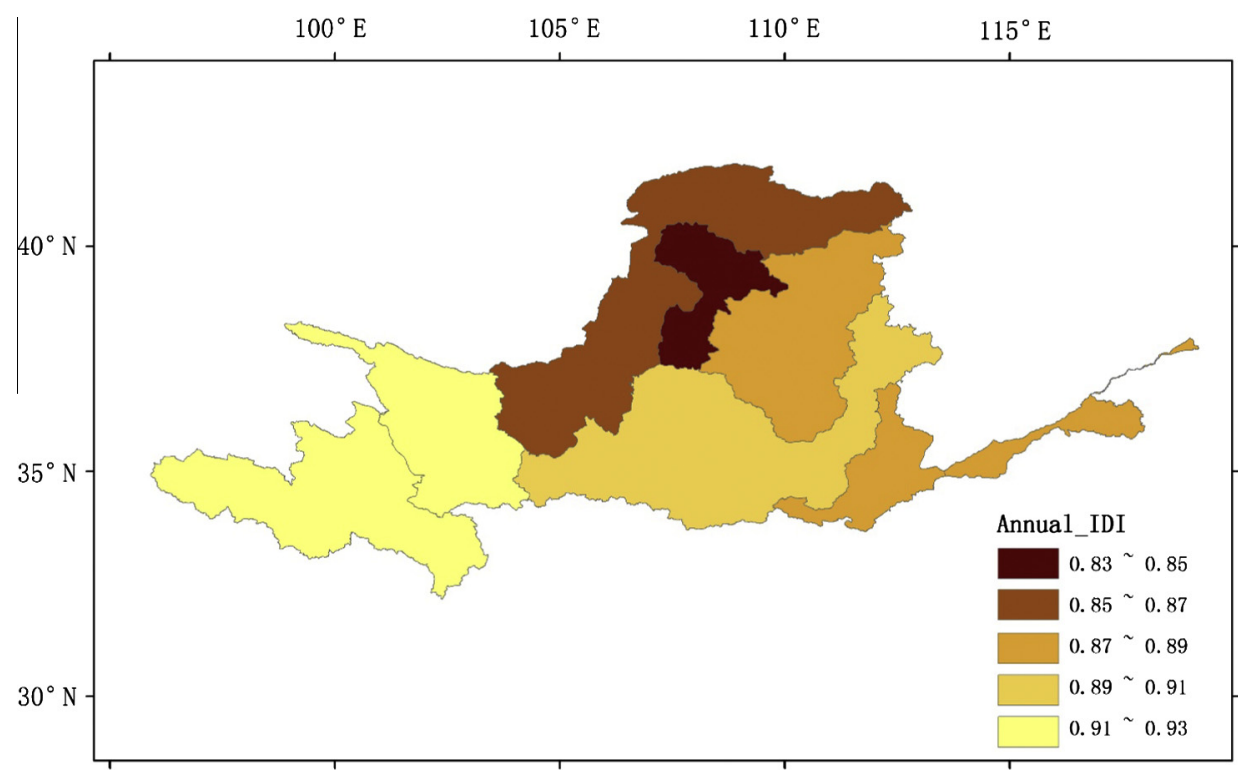

Fig. 3. The spatial distribution of average annual IDI in the Yellow River basin. 

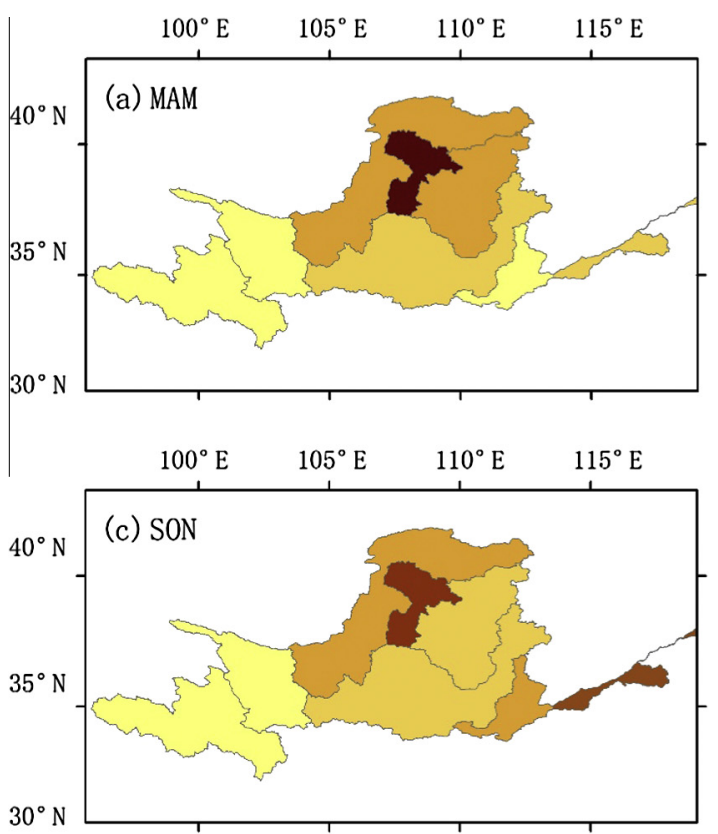
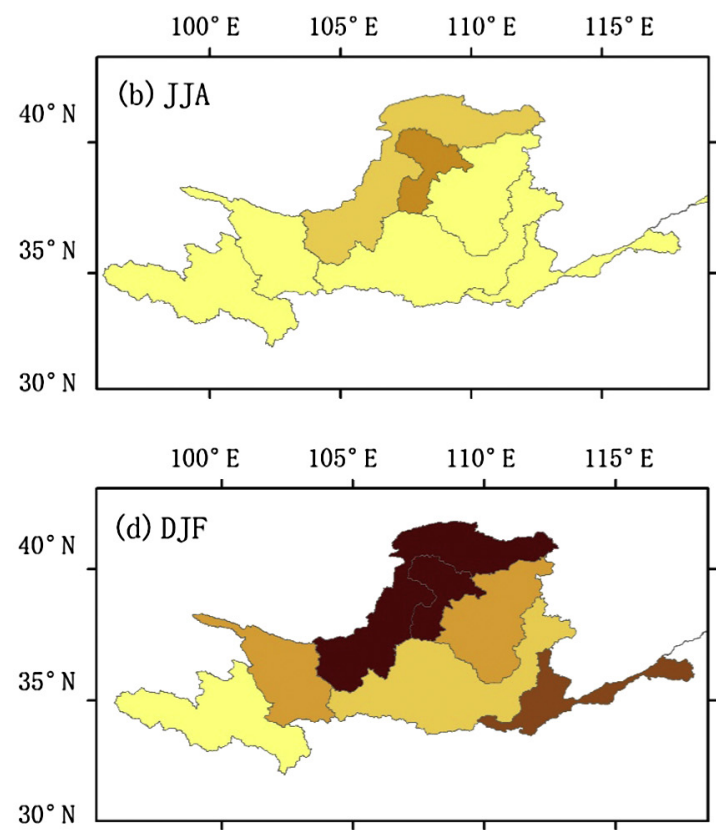

Seasonal_IDI

$\begin{array}{llll}0.7 & 0.74 & 0.78 & 0.82\end{array}$

Fig. 4. The spatial distribution of average seasonal IDI in the Yellow River basin, a, b, c, and d represent spring, summer, autumn, and winter, respectively.

Table 4

The trends of monthly IDI in the eight subzones in the Yellow River basin.

\begin{tabular}{|c|c|c|c|c|c|c|c|c|c|c|c|c|}
\hline Subzones & January & February & March & April & May & June & July & August & September & October & November & December \\
\hline 26 & 0.55 & 0.50 & -0.62 & -1.92 & 1.04 & 1.12 & -0.94 & $-2.05^{*}$ & 0.26 & -1.19 & -0.88 & -1.21 \\
\hline 28 & -0.11 & 0.71 & -1.25 & -1.48 & -0.04 & -0.40 & -0.27 & -0.55 & 0.58 & -1.12 & -1.04 & -1.19 \\
\hline 29 & 0.57 & 0.91 & -1.22 & $-2.48^{*}$ & -0.22 & 0.47 & -0.63 & -1.28 & -0.23 & -1.29 & -1.57 & -1.29 \\
\hline 31 & -0.04 & 0.65 & $-2.15^{*}$ & $-2.65^{*}$ & -0.90 & 0.22 & -1.15 & 0.14 & 0.47 & -0.65 & $-2.12^{*}$ & -0.93 \\
\hline 33 & -1.64 & -0.47 & 0.02 & -1.45 & -0.13 & 1.50 & -0.90 & -0.32 & 0.18 & -0.30 & -1.66 & -1.44 \\
\hline 36 & -0.73 & 0.55 & -0.88 & -0.62 & $2.50^{*}$ & 0.14 & 0.43 & 0.30 & 0.73 & -1.44 & -1.09 & -0.16 \\
\hline 40 & -0.73 & -0.11 & -1.38 & -1.86 & 0.66 & -0.47 & 0.55 & -0.10 & 0.86 & -0.42 & -1.80 & -0.83 \\
\hline 41 & 0.18 & -0.18 & 1.57 & 0.04 & -0.09 & -0.28 & 0.40 & -0.29 & -0.72 & -0.14 & -0.91 & 0.26 \\
\hline
\end{tabular}

" Denotes significant at $95 \%$ confident levels.

Table 5

The trends and persistence of drought in the eight subzones.

\begin{tabular}{lll}
\hline Subzones & Annual IDI & Hurst index \\
\hline 26 & -0.13 & 0.51 \\
28 & -1.33 & 0.45 \\
29 & -1.51 & 0.52 \\
31 & $-2.34^{*}$ & 0.50 \\
33 & -0.88 & 0.48 \\
36 & -0.13 & 0.40 \\
40 & -1.30 & 0.46 \\
41 & -0.27 & 0.52 \\
\hline
\end{tabular}

Denotes significant at 95\% confident levels.

management and mitigation. According to the law of mutual change of quality and quantity and variable fuzzy set theory outlined in Section 3.2, the qualitative change points of drought in the eight subzones were calculated and shown in Table 6. Table 6 indicates that the Yellow River basin has a noticeable spatial characteristic in terms of the qualitative change points of drought. The subzone 36 located in the downstream of the basin has 4 qualitative change points, ranking the first place, whilst subzone 31 has no qualitative change point, ranking the last place. The upstream (subzone 33 and 41) only have one qualitative change
Table 6

The qualitative change points of drought in the eight subzones.

\begin{tabular}{lll}
\hline Subzones & Number & Qualitative change points \\
\hline 26 & 3 & $1957,1981,1999$ \\
28 & 1 & 2005 \\
29 & 3 & $1980,1982,2005$ \\
31 & 0 & - \\
33 & 1 & 1980 \\
36 & 4 & $1960,1970,1986,1988$ \\
40 & 2 & 1978,1999 \\
41 & 1 & 1969 \\
\hline
\end{tabular}

point. Generally, the downstream has more qualitative change points than the upstream, partly because the anthropogenic impacts on the downstream is more intensified than upstream. Since runoff affected by climate change and anthropogenic activities has a high weight in IDI, these qualitative change points may be caused by the combined influence of climate change and intensifying human activities.

ENSO events are closely associated with patterns of flood and drought in various regions of the world and exert strong impacts on climates on local and regional scale by means of teleconnections influencing the combined ocean-atmosphere and land systems 


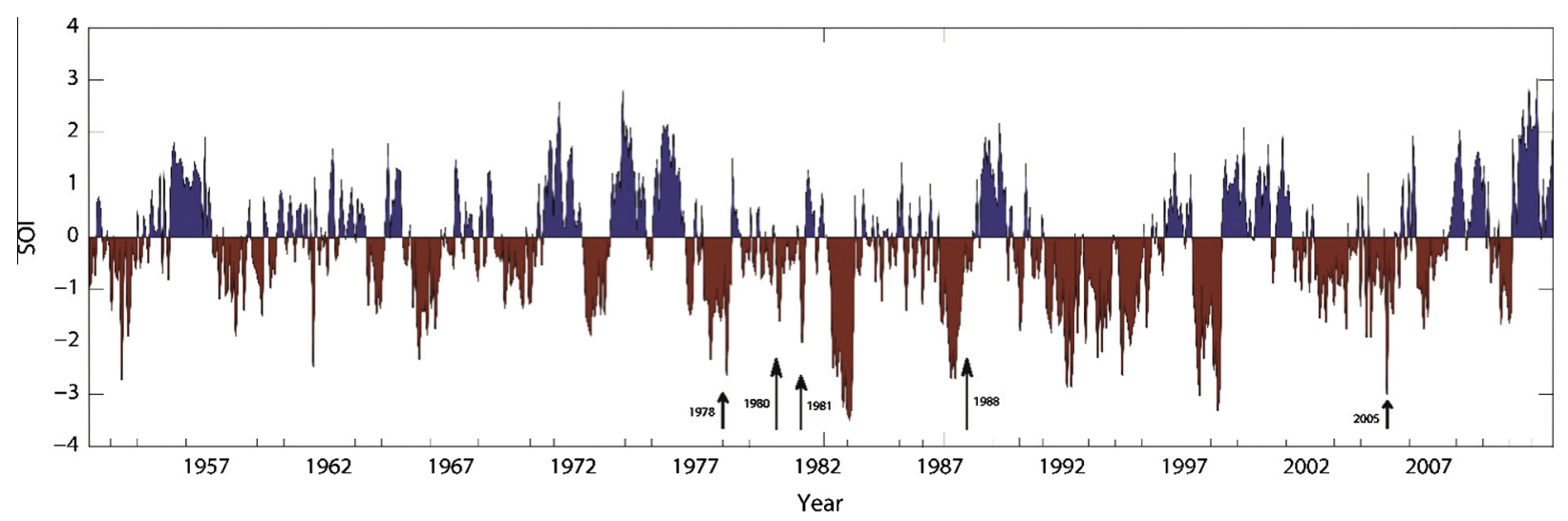

Fig. 5. Monthly SOI series covering 1952-2011.

Table 7

The detailed information of the four major reservoirs in the Yellow River.

\begin{tabular}{lllcl}
\hline Reservoirs & Location & $\begin{array}{l}\text { Height } \\
(\mathrm{m})\end{array}$ & $\begin{array}{l}\text { Storage } \\
\left(10^{9} \mathrm{~m}^{3}\right)\end{array}$ & $\begin{array}{l}\text { Time of } \\
\text { completion }\end{array}$ \\
\hline Sanmenxia & Middle reaches & 335 & 9.7 & September 1960 \\
Liujiaxia & Upper reaches & 147 & 5.7 & October 1968 \\
Longyangxia & Upper reaches & 178 & 27.6 & October 1986 \\
Xiaolangdi & Middle reaches & 160 & 12.7 & October 1999 \\
\hline
\end{tabular}

(Glantz et al., 1991). Previous studies have showed that the ENSO events can lead to decreased rainfall in the source regions of the Yellow River, and the interannual and seasonal variation of the Yellow River water discharge over the past 50 years were closely linked with the impact of ENSO events (Wang et al., 2001, 2006). It can be seen from Fig. 5 that the SOI values in the years 1978, $1980,1981,1988$, and 2005 are very low, indicating the occurrence of ENSO events Importantly, the timing of these low SOI values are corresponding to some of the low IDI values. Hence, it is expected that the ENSO events may lead to some of the qualitative change points of annual IDI series (i.e. droughts) in the Yellow River basin. Since the main goal of this study is to develop the integrated drought index, to physically explore the relationship between ENSO and droughts is not within the scope of this study and should be pursued in the future.

Among different kinds of human activities in river drainage basin, the construction of dams and reservoirs is one of the most direct ways to manipulate water resources (Wang et al., 2006), which possibly leads to change points of runoff, thus likely resulting in qualitative change points of annual IDI series. There are four most influential reservoirs along the mainstream of the Yellow River, namely, Sanmenxia, Liujiaxia, Longyangxia, and Xiaolangdi reservoirs (Fuggle et al., 2000). Their detailed information is illustrated in Table 7. It can be obviously observed from Table 7 that the completion time of the four major reservoirs in the Yellow River well matches the identified qualitative change points of 1960, 1969, 1986, and 1999 in the Yellow River basin.

Therefore, the identified qualitative change points of annual IDI series in the Yellow River basin may be mainly caused by the joint influences of ENSO events and the construction of dams and reservoirs.

\subsection{Discussions}

Many previous papers also studied the drought-related issues in the Yellow River basin (Xie and Fu, 2004; Shiau et al., 2007; Peng et al., 2011; She and Xia, 2013; Xu et al., 2014). Peng et al. (2011) and Xu et al. (2014) pointed out that the drought risk of the Loess Plateau is high, which is generally similar to what we found in this study. The results in this study indicate that drought risk increases from south to north in the Yellow River basin, which is consistent with the finding of She and Xia (2013). Besides, She et al. (2013) also found that the drought risk in northern portion of the midstream of the Yellow River is higher than that in the rest parts, which is similar to the results of the present study. Therefore, after being compared with other previous investigations about drought in the Yellow River basin, the results based on IDI are solid and reliable in this present study.

The present study attempts to explain the causes of change points of annual IDI series on the perspective of climate change and anthropogenic activities. ENSO events and the construction of dams and reservoirs were chose to represent climate change and anthropogenic activities, respectively. In practice, in addition to ENSO events and the construction of dams and reservoirs, some other factors such as Arctic Oscillation, land use/land cover, irrigation, and water and soil conservation probably also have a strong impact on these change points. However, some data are not available. Additionally, this is not the major objective in this study. To quantitatively attribute the droughts variations need to be further studied in the future.

The constructed IDI contains the information of meteorological, hydrological, and agricultural factors through determining their weights based on the entropy weight method that is an objective method for weight determination. The calculated weights primarily depend on the variation of evaluating object. However, the variation of soil moisture data is greatly smaller than runoff or precipitation. Therefore, the weight of soil moisture is very low, and IDI primarily contains the useful information of precipitation and runoff, without containing much useful information of soil moisture. Thus, the IDI cannot capture the actual drought duration in terms of agricultural factor to a certain degree. Notably, no single drought index can include all the aspects of droughts and meets the requirements of all applications since drought indicators are linked to certain drought properties (Burke and Brown, 2008). To construct a more robust and comprehensive drought index with soil moisture assigned more weights objectively is not within the scope of this study and should be pursued in the future. Rather, we propose a new framework for constructing a multivariate, multi-index drought-modeling approach for drought assessments. In addition, IDI was found to be highly consistent with SPI and SSFI and, more importantly, sensitive to the onset of drought and easily captures its onset. Furthermore, IDI has a better ability to reflect the persistence of drought than SPI which only contains the variation of precipitation. As drought has a fuzzy nature, the calculation of IDI based on variable fuzzy set theory is reasonable, which can be used to objectively reflect drought characteristic and its evolution. In general, this study provides a new thought in constructing an integrated indicator for drought assessment. 


\section{Conclusions}

Drought indicator based on one single variable (e.g. precipitation, runoff, or soil moisture) cannot comprehensively reflect the realistic situation of drought. Therefore, it is very necessary to construct an integrated indicator for drought assessment. Given the fuzzy nature of drought, variable fuzzy set theory was applied to construct IDI combining meteorological, hydrological, and agricultural factors. The entropy weight method was used to determine their weights objectively. The drought persistence in the near future was analyzed based on the Rescaled Range (R/S) analysis. Furthermore, the law of mutual change of quality and quantity was utilized to identify qualitative change points of drought in the Yellow River basin. The primary conclusions are as follows:

(1) IDI has a high consistence with SPI and SSFI. SPI is more sensitive to capture the onset of drought than SSFI, whilst SSFI exhibits more reliable drought persistence than SPI. Generally, IDI has the same ability with SPI in capturing drought onset and has the same ability with SSFI in capturing drought persistence, primarily due to its combination with meteorological, hydrological, and agricultural drought characteristics. Therefore, the calculated IDI is reliable and comprehensive indicator for drought assessment.

(2) The annual IDI in the Yellow River basin has a noticeable spatial difference. In general, the upstream has a larger IDI value than the middle and downstream, and IDI decreases from south to north. On seasonal scale, the drought in spring and winter is more severe than other seasons, and that in winter is the most severe, while that in summer is the least severe. The drought pattern of the upstream has little variation during different seasons, whilst the drought patterns of the middle and downstream of the Yellow River have a noticeable change during different seasons.

(3) Generally, the IDI of the Yellow River basin is dominated by an insignificantly downward trend, and the decreasing months are primarily concentrated in March, April, October, November, and December. However, for February, the basin is primarily characterized by an insignificantly increasing trend. On the whole, the decreasing trend of IDI in the middle stream is more obvious than the rest parts of the basin. The decreasing trends of IDI in the headwaters area and middle stream will be persistent, whilst the downward trend of IDI in the section between Tangnaihai and Lanzhou stations and the downstream will be opposite in the near future.

(4) Some qualitative change points of annual IDI series were identified in the Yellow River basin, and those are closely linked with ENSO events and the construction of dams and reservoirs.

\section{Acknowledgements}

This research was supported by the National Major Fundamental Research Program (2011CB403306-2), the National Natural Fund Major Research Plan (51190093) and the Natural Science Foundation of China (51179148, 51179149, and 51309188), Water conservancy project special public welfare industry scientific research funds (201501058), the Key Innovation Group of Science and Technology of Shaanxi (2012KCT-10), the China Scholarship Council and China Postdoctoral Science Foundation (2015M570139).

\section{References}

Alley, W.M., 1984. The palmer drought severity index: limitations and assumptions. J. Appl. Meteorol. 23 (7), 1100-1109.
American Meteorological Society (AMS), 2004. Statement on meteorological drought. Bull. Am. Meteorol. Soc. 85, 771-773.

Burke, E.J., Brown, S.J., 2008. Evaluating uncertainties in the projection of future drought. J. Hydrometeor. 9, 292-299.

Chen, S.Y., 2012a. Variable sets-the development of variable fuzzy sets and the application in assessment of water resource. Math. Pract. Theory 42, 92-101.

Chen, S.Y., 2012b. Variable sets and the theorem and method of optimal decision making for water resource system. J. Hydraulic Eng. 43, 1066-1074.

Chen, S.Y., Guo, Y., 2006. Variable fuzzy sets and its application in comprehensive risk evaluation for flood-control engineering system. Fuzzy Optim. Decis. Making 5, 153-162.

Dai, A., Trenberth, K.E., Qian, T.T., 2004. A global dataset of palmer drought severity index for 1870-2002: relationship with soil moisture and effects of surface warming. J. Hydrometeorol. 5 (6), 1117-1130. http://dx.doi.org/10.1175/JHM386.

Dalezios, N.R., Loukas, A., Vasiliades, L., Liakopoulos, E., 2000. Severity-duration frequency analysis of droughts and wet periods in Greece. Hydrol. Sci. J. 45 (5), $751-770$.

Daufresne, M., Lengfellner, K., Sommer, U., 2009. Global warming benefits the small in aquatic ecosystems. Proc. Natl. Acad. Sci. USA 106 (31), 12788-12793.

Federal Emergency Management Agency, 1995. National Mitigation Strategy: Partnerships for Building Safer Communities. FEMA, Washington, DC.

Fu, G.B., Chen, S.L., Liu, C.M., et al., 2004. Hydro-climatic trends of the Yellow River basin for the last 50 years. Clim. Change 65 (1), 149-178.

Fuggle, R., Smith, W.T., Hydrosult Canada Inc., Agrodev Canada Inc., 2000. Large dams in water and energy resource development in The People's Republic of China (PRC). Country Review Paper Prepared as an Input to the World Commission on Dams, Cape Town. <www.dams.org>.

Glantz, M.H., Katz, R.W., Nicholls, N., 1991. Teleconnections linking World Wide climatic anomalies. Cambridge University Press, Cambridge, UK.

Guttman, N.B., 1998. Comparing the palmer drought index and the standardized precipitation index. J. Am. Water Resour. Assoc. 34 (1), 113-121.

Guttman, N.B., Wallis, J.R., Hosking, J.R.M., 1992. Spatial comparability of the Palmer drought severity index. J. Am. Water Resour. Assoc. 28 (6), 1111-1119.

Hamed, K.H., Rao, A.R., 1998. A modified Mann-Kendall trend test for autocorrelated data. J. Hydrol. 204, 182-196.

Hao, Z.C., Aghakouchak, A., 2013. Multivariate standardized drought index: a parametric multi-index model. Adv. Water Resour. 57, 12-18.

Hosking, J.R.M., 1984. Modeling persistence in hydrological time series using fractional differencing. Water Resour. Res. 20 (12), 1898-1908.

Huang, S.H., Hou, B.B., Chang, J.X., et al., 2014a. Copulas-based probabilistic characterization of the combination of dry and wet conditions in the Guanzhong Plain, China. J. Hydrol. 519, 3204-3213.

Huang, S.H., Chang, J.X., Huang, O., et al., 2014b. Spatio-temporal changes and frequency analysis of drought in the Wei river basin, China. Water Resour. Manage. 28 (10), 3095-3110.

Jing, L.P., Michael, L.N., Huang, J.Z., 2007. An entropy weighting k-means algorithm for subspace clustering of high-dimensional sparse data. IEEE Trans. Knowl. Data Eng. 19 (8), 1026-1040.

Kao, S.C., Govindaraju, R.S., 2010. A copula-based joint deficit index for droughts. J. Hydrol. 380, 121-134.

Kim, T.W., Valdés, J.B., Yoo, C., 2003. Nonparametric approach for estimating return periods of droughts in arid regions. J. Hydrol. Eng. 8 (5), 237-246. http:// dx.doi.org/10.1061/(ASCE)1084-0699(2003) 8:5(237).

Lei, J.Q., Huang, Q., Wang, Y.M., 2014. Variable fuzzy evaluation on comprehensive divisions of drought in the Wei River basin. SHULI XUEBAO 45 (5), 574-584.

Leng, G., Tang, Q., Huang, M., Hong, Y., Leung, L.R., 2015a. Projected changes in mean and interannual variability of surface water over continental China. Sci. China Earth Sci. 58, 739-754.

Leng, G., Tang, Q., Rayburg, S., 2015b. Climate change impacts on meteorological, agricultural and hydrological droughts in China. Global Planet. Change 126, 2334.

Li, J.Z., Tan, S.M., Wei, Z.Z., et al., 2014. A new method of change point detection using variable fuzzy sets under environmental change. Water Resour. Manage. 28 (14), 5125-5138.

Liang, X., Lettenmaier, D.P., Wood, E.F., et al., 1994. A simple hydrologically based model of land surface water and energy fluxes for GSMs. J. Geophys. Res. 99, $14415-14428$.

Liang, X., Lettenmaier, D.P., Wood, E.F., 1996. One-dimensional statistical dynamic representation of subgrid spatial variability of precipitation in the two-layer variable infiltration capacity model. J. Geophys. Res. 101, 21403-21422.

Liu, X.W., 2007. Parameterized defuzzification with maximum entropy weighting function-another view of the weighting function expectation method. Math. Comput. Modell. 45 (1-2), 177-188.

Ma, M., Ren, L., Singh, V.P., et al., 2015. Evaluation and application of the SPDI-JDI for droughts in Texas, USA. J. Hydrol. 521, 34-45.

McKee, T.B., Doesken, N.J., Kliest, J., 1993. The relationship of drought frequency and duration to time scales. Paper Presented at the 8th Conference of Applied Climatology, Am. Meterol. Soc., Anaheim, Calif.

Meng, Q.S., 1989. Information theory [M]. Xi'An Jiaotong University Press, Xi'An, pp. $19-36$.

Mishra, A.K., Singh, V.P., 2010. A review of drought concepts. J. Hydrol. 391, 202216. http://dx.doi.org/10.1016/j.jhydrol.2010.07.012.

Mitchell, J.M., Dzerdzeevskii, B., Flohn, H., 1966. Climate Change, WHO Technical Note 79. World Meteorological Organization, Geneva, p. 79. 
Moreira, E.E., Coelho, C.A., Paulo, A.A., Pereira, L.S., Mexia, J.T., 2008. SPI-based drought category prediction using loglinear models. J. Hydrol. 354, 116-130. http://dx.doi.org/10.1016/j.jhydrol.2008.03.002.

Nijssen, B., Lettenmaier, D.P., Liang, X., et al., 1997. Streamflow simulation for continental-scale river basins. Water Resour. Res. 33, 711-724.

Nijssen, B., Schnur, R., Lettenmaier, D.P., 2001. Global retrospective estimation of soil moisture using the variable infiltration capacity land surface model, 198093. J. Clim. 14, 1790-1808.

Oliver, R., Ballester, J.L., 1996. Rescaled range analysis of the asymmetry of solar activity. Sol. Phys. 169 (1), 215-224.

Pan, M., Wood, E.F., 2009. A multiscale ensemble filtering system for hydrologic data assimilation. Part II: application to land surface modeling with satellite rainfall forcing. J. Hydrometeor. 10, 1493-1506.

Peng, G.H., Xia, J., Ma, X.F., et al., 2011. Analysis on drought frequency distribution and digital characteristics of number of turns of the Yellow River basin. Yellow River 6 (in Chinese).

Pongracz, R., Bogardi, I., Duckstein, L., 1999. Application of fuzzy rule-based modeling technique to regional drought. J. Hydrol. 224, 100-114.

Qiu, W.H., 2002. Management Decision and Applied Entropy [M]. China Machine Press, Beijing, pp. 193-196.

Robock, A., Vinnikov, K.Y., Srinivasan, G., et al., 2000. The global soil moisture data bank. Bull. Amer. Meteorol. Soc. 81, 1281-1299.

Sadri, S., Burn, D.H., 2012. Nonparametric methods for drought severity estimation at ungauged sites. Water Resour. Res. 48, W12505.

Safavi, H.R., Esfahani, M.K., Zamani, A.R., 2014. Integrated index for assessment of vulnerability to drought, case study: Zayandehrood river basin, Iran. Water Resour. Manage. 28, 1671-1688.

Shao, X.M., Yan, C.R., Wei, H.B., 2006. Spatial and temporal structure of precipitation in the Yellow River basin based on Kriging method. Chin. J. Agrometeorol. 27 (2), 65-69 (in Chinese).

Sharma, A., 2000. Seasonal to interseasonal rainfall probabilistic forecasts for improved water supply management: Part 3-A nonparametric probabilistic forecast model. J. Hydrol. 239, 249-258.

She, D.X., Xia, J., 2013. The spatial and temporal analysis of dry spells in the Yellow River basin, China. Stoch. Environ. Res. Risk Assess. 27, 29-42.

Sheffield, J., Wood, E.F., 2007. Characteristics of global and regional drought, 1950 2000: analysis of soil moisture data from off-line simulation of the terrestrial hydrologic cycle. J. Geophys. Res. 112, D17115.
Shi, X., Wood, A.W., Lettenmaier, D.P., 2008. How essential is hydrologic model calibration to seasonal streamflow forecasting? J. Hydrometeor. 9, 1350-1363.

Shiau, J.T., Feng, S., Nadargjah, S., 2007. Assessment of hydrological droughts for the Yellow River, China, using copulas. Hydrol. Process. 21, 2157-2163.

Shukla, S., Wood, A.W., 2008. Use of a standardized runoff index for characterizing hydrologic drought. Geophys. Res. Lett. 35, L02405.

Vicente-Serrano, S.M., López-Moreno, J.I., 2005. Hydrological response to different time scales of climatological drought: an evaluation of the standardized precipitation index in a mountainous mediterranean basin. Hydrol. Earth Syst. Sci. 9, 523-533.

Wang, G., Shen, Y., Liu, S., 2001. On the characteristics of response of precipitation and runoff to the ENSO events in the source regions of the Yellow River. J. Glaciol. Geocryol. 23, 16-21 (in Chinese with English abstract).

Wang, H.J., Yang, Z.S., Saito, Y., et al., 2006. Interannual and seasonal variation of the Huanghe (Yellow River) water discharge over the past 50 years: connections to impacts from ENSO events and dams. Global Planet. Change 50, 212-225.

Wang, C.S.H., Bauwens, L., Hsiao, C., 2013. Forecasting a long memory process subject to structural breaks. J. Econometrics 177 (2), 171-184.

Western Governors' Association, 1996. Drought Response Action Plan. WGA, Denver, CO.

Wilhite, D.A., 2000. Drought as a natural hazard: concepts and definitions. In: Wilhite, D.A. (Ed.), Drought: A Global Assessment, Hazards Disasters Ser., vol. I Routledge, New York, pp. 3-18.

Wilhite, D.A., Glantz, M.H., 1985. Understanding the drought phenomenon: the role of definitions. Water Int. 10, 111-120.

Xie, Y.G., Fu, Q., 2004. Analysis of famines caused by heavy floods and droughts in China. Nat. Sci. 2 (2), 25-32.

Xu, K., Yang, D.W., Yang, H.B., et al., 2014. Spatio-temporal variation of drought in China during 1961-2012: a climatic perspective. J. Hydrol. 526, 253-264.

YRCC (Yellow River Conservancy Commission), 2008. Yellow River Water Resources Bulletin. China WaterPower Press, Beijing.

YRCC (Yellow River Conservancy Commission), 2010. Yellow River Water Resources Bulletin. China WaterPower Press, Beijing.

Zhang, X., Tang, Q., Pan, M., et al., 2014. A long-term land surface hydrologic fluxes and states dataset for China. J. Hydrometeorol. 15, 2067-2084.

Zou, Z.H., Yun, Y., Sun, J.N., 2006. Entropy method for determination of weight of evaluating in fuzzy synthetic evaluation for water quality assessment indicators. J. Environ. Sci. 18 (5), 1020-1023. 